\title{
Analysis of Scientific Construction of Software Courses System in Colleges
}

\author{
Yong Zhu, Dapeng Zhou, Fei Zhan \\ Gongqing College, Nanchang University, Gongqingcheng City, Jiangxi, 332020
}

Keywords: Software Courses System, Construction Method, Scientific Study

\begin{abstract}
With the development of "Internet +" mode of economic restructuring, software engineering professionals face many opportunities and challenges. The paper expounds the supportive role of professional curriculum system in personnel training, analyzes the relationship between post requirements of software talents and software engineering professional knowledge system, explores the education mode that the school-enterprise cooperates to develop the software engineering training program, and software engineering course structure.
\end{abstract}

\section{Introduction}

Talents cultivation is a basic task of Colleges. Teaching is the main channel for cultivating talents in teaching Colleges. The establishment of curriculum system is the key link in the teaching of Colleges. Developing a perfect professional curriculum system is to improve the quality of professional teaching at the core is to enhance the competitiveness of university students employment key. Software engineering is a discipline that studies how to construct and maintain effective, practical and high-quality software by using engineering methods. It is one of the fastest growing disciplines in the field of information. There are over 400 software engineering specialties in the country. Due to the difference of school orientation and professional characteristics, the revised program of software engineering professionals and curriculums varies from university to university. In order to adapt talents training program to social development and teaching reform, it is necessary to revise the talent training program continuously, Therefore, the professional curriculum system has changed accordingly. Whether the changed professional curriculum system meets the requirements of teaching and personnel training is a difficult problem for planners. Therefore, it is necessary to evaluate the professional curriculum system. Based on the explanation of the basic principles of the index construction, this study focuses on the construction of the evaluation index system, and determines the primary and secondary index system of curriculum system evaluation through literature analysis method and Delphi method. By using Analytic Hierarchy Process to determine the weight of the evaluation index system of the course system, the evaluation system of graduates is adopted to evaluate the curriculum system of the 2010 version of software engineering professionals in our school. The evaluation results meet the requirements. This research has certain reference value for the formulation and evaluation of curriculum system in software engineering professionals training program in Colleges [1].

\section{School software engineering talent training objectives}

The goal of personnel training is to describe the specifications, methods and employment of personnel training. It is necessary to take into account the characteristics of specialties, cultivate the environment, the orientation of graduation, and other factors, highlight the characteristics of training, and reflect the pertinence. The fundamental task of applied higher education is to cultivate high-quality talents who adapt to the society, serve the society and promote the advance of the times [2]. Suzhou Institute of software engineering to market demand-oriented, emphasis on practice, skills and ability to apply training and outsourcing companies Education Group jointly run the school to take $3+1$ embedded school-enterprise education and training mode, the curriculum teaching, engineering practice, The industry concept of seamless integration. Both schools and enterprises jointly set up teaching syllabus, integrate teaching resources, and jointly participate in 
the implementation of personnel training programs. The school professional teachers in accordance with the syllabus in charge of professional foundation and part of the professional teaching work, business project manager responsible for curriculum training, professional internships and graduation internships and other practical teaching links, both inside and outside schools, closely around the enterprise software talent Job requirements, the basic theory and engineering practice of organic integration, project-driven, to stimulate student interest in learning and develop students' comprehensive ability to apply. In accordance with the goal of personnel training, Suzhou Institute of Software Engineering established software development and software testing two professional directions. Students in software development require basic knowledge and skills of software development, ability of thinking in engineering, master of software engineering norms, good professional ethics, teamwork ability and innovation ability. Students in software testing direction need to master the basic ideas and scientific system of software product quality assurance, master the basic content of software testing, test methods, techniques and tools, and track new theories, new knowledge and new technologies in software testing field. Strong logical thinking ability and good teamwork skills.

\section{Thoughts on the Construction of Software Engineering Course System in Colleges}

Curriculum system is to achieve the goal of professional training, is the main content of professional training programs, professionals should have the basic knowledge and ability to reflect the specific [3]. Curriculum system is directly related to the quality of personnel training. Therefore, we focus on the positioning of professional personnel training objectives, research professional and professional qualities constitute the elements, highlighting the practical ability and quality of engineering training, and gradually clear the ideas for the construction of specialized courses.

The construction of the core curriculum system is not a simple pile of difficult courses, but based on personnel training objectives, effective tailoring and adjustment of professional courses. Each core course should be able to undertake the task of training students' specialized knowledge and skills in one aspect, and the professional core courses should be able to be connected in a coherent manner. The core curriculum system should not only reflect the analysis of computer science problems, logical thinking to solve the problem, but also to reflect the specific methods and techniques of software engineering disciplines. The system of software engineering course in local applied colleges should not only be distinguished from the big system and big platform of "famous university", but also be distinguished from the system of skill-only teaching in vocational colleges. It should be based on "professional theoretical knowledge, focusing on the ability to train and quality training, "the goal of finding a balance between undergraduate education and vocational education to industry, business knowledge of job-specific personnel ability to build the curriculum specific requirements.

The students' ability of sustainable development is reflected in the ability to find and solve problems, job adaptability and so on. Develop good self-learning habits of students, arrange training courses of the project that can reflect the professional characteristics in the curriculum system, and cultivate students' abilities of finding problems, analyzing problems and solving problems. Prominent students to adapt to the position of training in the curriculum system can be arranged to reflect the industry, corporate management, post qualifications and elective courses so that students have early exposure to business, training and professional awareness of career thinking for students after graduation to be able to adapt well to lay a solid foundation for job needs.

\section{Curriculum system}

(1) To cultivate students' ideological, political, cultural and physical and mental qualities through public basic courses in general courses; and to train students in basic and simple courses to carry out preliminary software application and development capabilities in a simple and universal environment. (2) To cultivate the ability of students to use software engineering methods to carry out specific software design through the basic course of computer system in professional core 
courses; to train students' ability and practical ability to solve complex software design in the field of software engineering through the course of software engineering methodology. (3) In the course of professional development, through the database system design, Java application technology, B / S system software design, middleware technology and other courses to train students in the software development technology direction; through the introduction of service science, e-commerce system structure, service Trust and credibility, IT service management courses to develop students in software services engineering capabilities. (4) Expand students 'horizons through career development planning, team motivation and communication, cross-cultural management and entrepreneurship lectures in the quality development course to cultivate students' team spirit, management skills and coordination skills. (5) To cultivate software engineering talents who have both solid theoretical knowledge and practical ability through practical training course, business practice and graduation project.

Practice teaching, as an important part of undergraduate education in software engineering, relates to the quality and specialty construction of engineering talents. Our school closely combined with the "Regulations for Software Engineering Specialty of Higher Education Institutions" formulated in 2011, reconstructed the teaching links of traditional curriculum experiment, comprehensive curriculum design, project training, professional practice and graduation design, The collaborative, mutually reinforcing and evaluable practice teaching system shown by the three schools, enterprises and students mentioned above focuses on cultivating students' abilities in the following six aspects: the use and experiment skills of tools, the ability of engineering design and implementation, the ability of assessment and testing, Teamwork and communication skills, process management and control capabilities, domain-oriented application capabilities.

Students in the joint laboratory curriculum and integrated curriculum design, verification, research to complete the experiment, emphasizing students comprehensive use of the knowledge of multiple courses to solve the problem of ability, more emphasis on systems analysis, design and integration capabilities, Strengthen the cultivation of independent practical ability and good quality of scientific research. Through the practice base, students can understand the needs of enterprises, increase their perceptual awareness and stimulate professional interest in learning. At the same time, they plan their career according to their own actual conditions and become familiar with the business processes of their enterprises, increase their actual combat experience and enhance their competitiveness in employment. (2) Employ both enterprise experts who have rich experience in engineering practice and good teaching level as part-time teachers in the school to formulate teaching plans, design teaching contents, provide practical training projects and conduct case teaching together with the teachers in the school. Project training is generally arranged in the second semester of summer, the project source is mainly provided by schools and cooperative enterprises in order to provide students with a real software project development process, especially for students to gain personal knowledge of what they learned. At the same time, part-time teachers through the process of enterprise selection for outstanding software engineering talent [4]. (3) The enterprises provide internship opportunities for students to solve the high expenses that enterprises need to pay in the training of employees, at the same time, shorten the period of talent cultivation and realize the seamless connection of students training to actual combat. Although there is only one-word difference between "training" and "actual combat", there is an essential difference: if the student can not achieve the expected result in the training, it only manifests as "<60" or " $>60$ " However, only "0" or "1" exists in actual combat, which will bring extremely serious consequences. This is obvious for students' performance in training. (4) At the same time of carrying out theoretical and experimental teaching, full-time school teachers strengthen cooperation with enterprises, understand the development trend of new technologies and solve technical problems for enterprises. For young masters, Ph.D., encourage them to the enterprise to further exercise their engineering practice ability, and gradually accumulate, enrich the "case base" and grow into a qualified "double teacher" teacher [5]. 


\section{Conclusions}

Summarize and classify the technical route to be followed in teaching research, a two-level comprehensive evaluation index system suitable for the evaluation of software engineering course system in Colleges is established. The method of AHP is used to give weight value to each index of evaluation index system. Jilin University of Technology and Engineering College Software Engineering 2010 version of the talent training program corresponding to the curriculum system as an example for the actual evaluation analysis, the results show that the research method is appropriate and feasible. Due to the limitation of research time, the limited theoretical level of subject team, and the lack of experience, there are some problems in this research, such as the model is not perfect and the index is not refined enough, and further research is needed.

\section{Acknowledgements}

Fund Project: This article is 2016 Jiangxi Province teaching reform project "based on the work process software technology curriculum system construction and research.

The stage results of (JXJG-16-31-5)

\section{References}

[1] Chang Yunfei. Reflections on Cultivating Applied Talents in Local Universities under the Background of Supply-side Reform in Higher Education [J]. Journal of Xichang University, 2017,29 (1): 105-107 + 115 .

[2] Wu Gang, Sun Yanzhong. Application-based higher education curriculum system construction and employment preparation [J]. Panzhihua University, 2015,32 (5): 100-102.

[3] Wei Xuefeng. Application Oriented Software Engineering Curriculum Architecture [J]. Computer Education, 2013 (21): 9-12.

[4] Pan Yi. Discussion on the Setting of Curriculum System of Software Engineering Specialty in Applied Universities [J]. Journal of Changsha University, 2008,22 (5): 98-100.

[5] Zhang Yongqiang, Zhang Mohua. Application-oriented undergraduate software engineering focused on practical teaching [J]. Computer Education, 2015 (12): 81-84. 